\title{
South to North Migration Patterns of Tuberculosis Patients Diagnosed in the Mexican Border with Texas
}

\author{
Jennifer S. Curry 1,2,9 Bassent Abdelbary ${ }^{1,3} \cdot$ Moncerrato García-Viveros $^{4}$. Juan Ignacio Garcia ${ }^{5} \cdot$ Marcel Yotebieng $^{6}$. \\ Adrian Rendon ${ }^{7} \cdot$ Jordi B. Torrelles ${ }^{5} \cdot$ Blanca I. Restrepo ${ }^{1,8,10}$
}

Accepted: 10 October 2021 / Published online: 18 October 2021

(c) The Author(s), under exclusive licence to Springer Science+Business Media, LLC, part of Springer Nature 2021

\begin{abstract}
The Mexican state of Tamaulipas serves as a migration waypoint into the US. Here, we determined the contribution of immigrants to TB burden in Tamaulipas. TB surveillance data from Tamaulipas (2006-2013) was used to conduct a cross-sectional characterization of TB immigrants (born outside Tamaulipas) and identify their association with TB treatment outcomes. Immigrants comprised $30.8 \%$ of TB patients, with $>99 \%$ originating from internal Mexican migration. Most migration was from South to North, with cities adjacent to the US border as destinations. Immigrants had higher odds of risk factors for TB [older age ( $\geq 65$ year old, OR 2.4, 95\% CI 2.1, 2.8), low education (OR 1.3, 95\% CI 1.2, 1.4), diabetes (OR 1.2, 95\% CI $1.1,1.4$ )], or abandoning treatment (adjusted OR $1.2,95 \% \mathrm{CI} 1.0,1.5$ ). There is a need to identify strategies to prevent TB more effectively in Tamaulipas, a Mexican migration waypoint.
\end{abstract}

Keywords Tuberculosis $\cdot$ Diabetes $\cdot$ Mexico-US border $\cdot$ Migration $\cdot$ Infectious diseases

\section{Introduction}

Foreign-born individuals bear a high proportion of the overall Tuberculosis (TB) burden in high-income countries [1]. In the US, immigrants account for $71.4 \%$ of all TB cases and $85 \%$ of the multidrug-resistant (MDR) TB cases, with Mexican nationals comprising nearly $20 \%$ in both cases $[2,3]$. The incidence of TB and MDR-TB in the US has

Blanca I. Restrepo

Blanca.i.restrepo@uth.tmc.edu

1 School of Public Health, University of Texas Health Science Center at Houston, Brownsville campus, Brownsville, TX, USA

2 Rollins School of Public Health, Emory University, Atlanta, GA, USA

3 College of Health Professions, University of Texas Rio Grande Valley, Edinburg, TX, USA

4 Secretaría de Salud de Tamaulipas, Ciudad Victoria, Tamaulipas, Mexico

5 Population Health Program, Texas Biomedical Research Institute, San Antonio, TX, USA

6 Division of General Internal Medicine, Department of Medicine, Albert Einstein College of Medicine, Bronx, NY, USA declined in the last decade, including US states bordering Mexico like California and Texas. Despite their reduction in TB incidence between 2009 and 2019 (California: from 6.7 to 5.3/100,000; Texas: 6.0 vs 4.0/100,000) [4-6], these two states remain among the top four with highest TB incidence [7]. Furthermore, in the Texas counties bordering Mexico, Mexican nationals comprise more than $60 \%$ of the TB patients [8].

7 Centro de Investigación, Prevención y Tratamiento de Infecciones Respiratorias CIPTIR, University Hospital of Monterrey, Universidad Autonoma de Nuevo Leon, Monterrey, Mexico

8 School of Medicine, South Texas Diabetes and Obesity Institute, University of Texas Rio Grande Valley, Edinburg, TX, USA

9 Present Address: Center for Translation Research and Implementation Science, National Heart, Lung, and Blood Institute, Bethesda, MD, USA

10 UTRGV-Edinburg Campus, 1214 W Schunior, Edinburg, TX, USA 
The Mexican region bordering the US houses a high number of vulnerable populations including, drug users, illegal immigrants, and most recently, COVID-19 patients [9-13]. The border has historically attracted immigrants from TB endemic areas like Southern Mexico and Central America [6, 14]. In recent years, immigrants have progressively accumulated in overcrowded confinements that favor Mycobacterium tuberculosis transmission. Not surprisingly, the six Mexican Border States (Baja California, Sonora, Chihuahua, Coahuila, Nuevo León, and Tamaulipas) account for $34.3 \%$ of all TB cases in Mexico, with TB incidence rates of up to $44.9 / 100,000$ in 2016, compared to $13.8 / 100,000$ nationally [15-18].

Mexico is considered an important migration corridor in the world, serving as a country of origin, a place of transit, and a destination for many immigrants expecting to enter the US [19, 20]. Within Mexico, Tamaulipas is a highly dynamic state. Annually, more than 50,000 individuals emigrate from Tamaulipas to settle in other Mexican states, e.g., Nuevo León, Veracruz, San Luis Potosí and Coahuila, and approximately another 30,000 emigrate to the US [21,22]. Nonetheless, this population loss is quickly made up by a similar influx of approximately 100,000 immigrants coming into Tamaulipas each year in search of better job opportunities and improved or safer lifestyles, mostly from other Mexican states, where the economy is depressed such as Veracruz, San Luis Potosí and Chiapas [21].

Among the Mexican-US Border States, Tamaulipas has the second highest burden of TB, and because of its geographical location, it serves as a migration waypoint. Elucidation of the migration patterns of TB patients in Tamaulipas would provide a deeper understanding of their contribution to TB incidence in this border state, and percolation to the US, but such studies are missing. The primary objective of this study was to determine the contribution of immigrants to increased TB cases in Tamaulipas, and identify their place of origin, migration destinations, sociodemographic characteristics and their likelihood of TB treatment success, when compared to local residents.

\section{Material and Methods}

\section{Ethics Review}

This study was approved by the institutional review board of the University of Texas Health Science Center at Houston (Human Subject IRB \# HSC-SPH-15-0489) and the Research Committee for the Secretaría de Salud de Tamaulipas (Human Subjects IRB\# 076/2015/CEI).

\section{Data Source and Study Population}

We used data collected for TB surveillance purposes between 2006 and 2013 by the Mexican Health Department (Secretaría de Salud de Mexico) for the state of Tamaulipas. These data included all the new TB cases among patients 18 years and older. Definitions were based on the official Mexican National TB program. Namely, TB diagnosis was based on the detection of acid-fast bacilli by smear microscopy or histopathology, culture or clinical findings. Further details on the procedure for selection of 8431 adults [18 years or older] with newly diagnosed TB patients were reported elsewhere [23].

\section{Measures and Definitions}

The primary exposure of interest was immigrant status of the TB patient, defined as "YES" for individuals reporting a place of birth outside of Tamaulipas. The dataset options included each Mexican state or "other countries". Adverse treatment outcomes included failed TB treatment (when the patient remains smear positive after five months of anti-TB drug treatment), relapse (when presenting new TB within one year of treatment completion), abandon (when lost to follow-up for more than three months), or death (during the course of TB treatment). Treatment was evaluated by merging individual outcomes and categorizing them as successful or not per World Health Organization (WHO) definitions [24]. Drug-resistant (DR) TB refers to resistance to any first-line antibiotic for TB, and MDR-TB indicates resistance to both isoniazid and rifampicin. Patient's characteristics, previously described in detail [23], included age, sex, occupation, undernutrition (determined clinically), diabetes (self-reported or blood confirmed), and excess alcohol consumption (self-reported), BCG vaccination based on scarring and HIV serology. Tamaulipas is divided into different sanitary jurisdictions, with those adjacent to the US referred to as "border" and others as "non-border" (Table S1).

\section{Statistical Analysis}

We used proportions or means to describe the distribution of variables. We first evaluated three aspects of migration among TB patients in Tamaulipas: The proportion of immigrant TB patients, their place of origin, and their predominant migration routes. The Chi-square test for trend was used to detect TB incidence rate changes over the eightyear period of study. The percent change over time was estimated using both the linear interpolation method and average annual percent change to account for year-to-year change. Associations between immigrant status and their 
sociodemographics, comorbidities and TB treatment outcomes were also evaluated. Univariable logistic regression models were employed to estimate odds ratios (OR) and 95\% confidence intervals assessing the differences in outcome across levels of co-variables. All multivariable logistic regression analysis included age and sex, and additional analysis was conducted with education status and comorbidities, in order to identify the independent contribution of place of birth to TB treatment success adjusted for potential confounders. All statistical tests were performed using STATA 14 (StataCorp. 2015. Stata Statistical Software: Release 14. College Station, TX: StataCorp LP) at a 5\% level of significance.

\section{Results}

\section{Participants Characteristics}

The characteristics of the study population were described previously [23]. Essentially, the mean age of the $8431 \mathrm{~TB}$ patients was 43 years and $65.5 \%$ were males. Nearly half were unemployed and $58 \%$ had at most a primary school education. More than $90 \%$ had pulmonary TB and $15.2 \%$ had an adverse TB treatment outcome. One fourth had diabetes and $5.3 \%$ had HIV.

We found that the average proportion of patients with TB who were immigrants was $30.8 \%$ over the eight years studied (range 18.6-37.8\%; Table S1). There were minor changes in the proportion of immigrants with TB over time, with the lowest in 2006 (18.6\%) and 2007 (26.4\%), and higher values and high between 2008 and 2013 [(range 30.8-37.8\%); trend $p$ value 0.526$]$. The TB incidence background was maintained similar over the eight-year study period (range $30.0-33.8 / 100,000$ per year; trend $p$ value 0.900 ; Table $\mathrm{S} 1$ ).

\section{Immigration Patterns}

Nearly all TB immigrants were born in other Mexican states (2577/2596, 99.3\%) with less than $1 \%$ originating from other countries. Nearly three-quarters (1906 of 2596, 73.4\%) were residing in border jurisdictions at the time of their TB diagnosis, with most in the cities of Reynosa (29.3\%), Nuevo Laredo (22.3\%) and Matamoros (16.8\%; Fig. 1). Most immigrant were born in four Mexican states: Chiapas $(n=181$, $2.2 \%)$, Nuevo Leon $(\mathrm{n}=255,3.0 \%)$, San Luis Potosi $(n=476,5.7 \%)$, and Veracruz $(n=903,10.7 \%)$. The most frequent destinations for immigrants originating from these four cities were as follows: TB patients originating from Chiapas were now mostly living in Nuevo Laredo (107/181, 59.1\%), Reynosa (34/181, 18.8\%), and Matamoros (23/181, $12.7 \%)$. Those from Nuevo Leon were now mostly in Reynosa $(85 / 255,33.3 \%)$ and Nuevo Laredo $(83 / 255,32.5 \%)$.
Those from San Luis Potosi had mainly emigrated to Matamoros (124/476, 26.1\%), Tampico (113/476, 23.7\%), Nuevo Laredo (83/476, 17.4\%), and Reynosa (70/476, 14.7\%). And the TB patients born in Veracruz were mainly residing in Reynosa (367/903, 40.6\%), Tampico (208/903, 23\%), Matamoros (129/903, 14.3\%), and Nuevo Laredo (83/903, 9.2\%) (Fig. 1).

\section{Characteristics of TB Patients Associated with Immigrant Status by Place of Birth}

Compared to local residents, immigrant TB patients born outside of Tamaulipas were older [(OR 1.5, 95\% CI 2.3, 1.6 for 41-64 year old vs. OR 2.4, 95\% CI 2.1, 2.8 for those older than 64 years], had a lower level of education (OR 1.3, 95\% CI 1.2, 1.4, up to primary school vs. higher education), decreased odds of BCG vaccination (OR $0.9,95 \%$ CI 0.8 , 0.98 ), and/or decreased odds of having a positive smear for acid-fast bacilli at the time of TB diagnosis (OR 0.8, 95\% CI 0.7, 0.9; Table 1). When evaluating comorbidities, immigrants with TB $v s$. those born in Tamaulipas had increased odds of diabetes (OR 1.2, 95\% CI 1.1, 1.4), and lower HIV/ AIDS (OR 0.7, 95\% CI 0.6, 0.9). When adjusting for sociodemographics, a lower odds of a positive AFB smear or higher odds of abandoning treatment remained significant (Table 1).

Analysis was also conducted based on the most frequent states of birth: Chiapas, Nuevo Leon, San Luis Potosi or Veracruz (Table 2). We found that the odds of HIV/AIDS was lower in immigrants from Chiapas (OR 0.2, 95\% CI 0.04, 0.7) or San Luis Potosi (OR 0.5, 95\% CI 0.3, 0.9). Type 2 diabetes was more prevalent in those born in San Luis Potosi (OR 1.6, 95\% CI 1.3, 1.9) and Veracruz (OR $1.2,95 \%$ CI 1.1, 1.4). Regarding TB clinical characteristics, there were no differences between local and immigrant TB patients in the prevalence of the pulmonary location, drug resistant TB or smear results, except for lower smear positivity for immigrants with TB from Veracruz. Regarding TB treatment outcomes, when compared to TB patients born in Tamaulipas (locals), immigrant born in Nuevo Leon had a two fold increased odds of TB treatment failure, and those born in Chiapas had 2.1-fold increased odds of TB relapse. When controlling for age, sex, education level, BCG vaccination, diabetes and HIV/AIDS, being an immigrant from Nuevo Leon remained associated with abandonment of treatment (OR 1.9, 95\% CI 1.2, 2.9; Table 1).

\section{Discussion}

We conducted a study aimed at understanding the epidemiology of TB among immigrants in Tamaulipas, a Mexican state bordering the US. We found that immigrants 


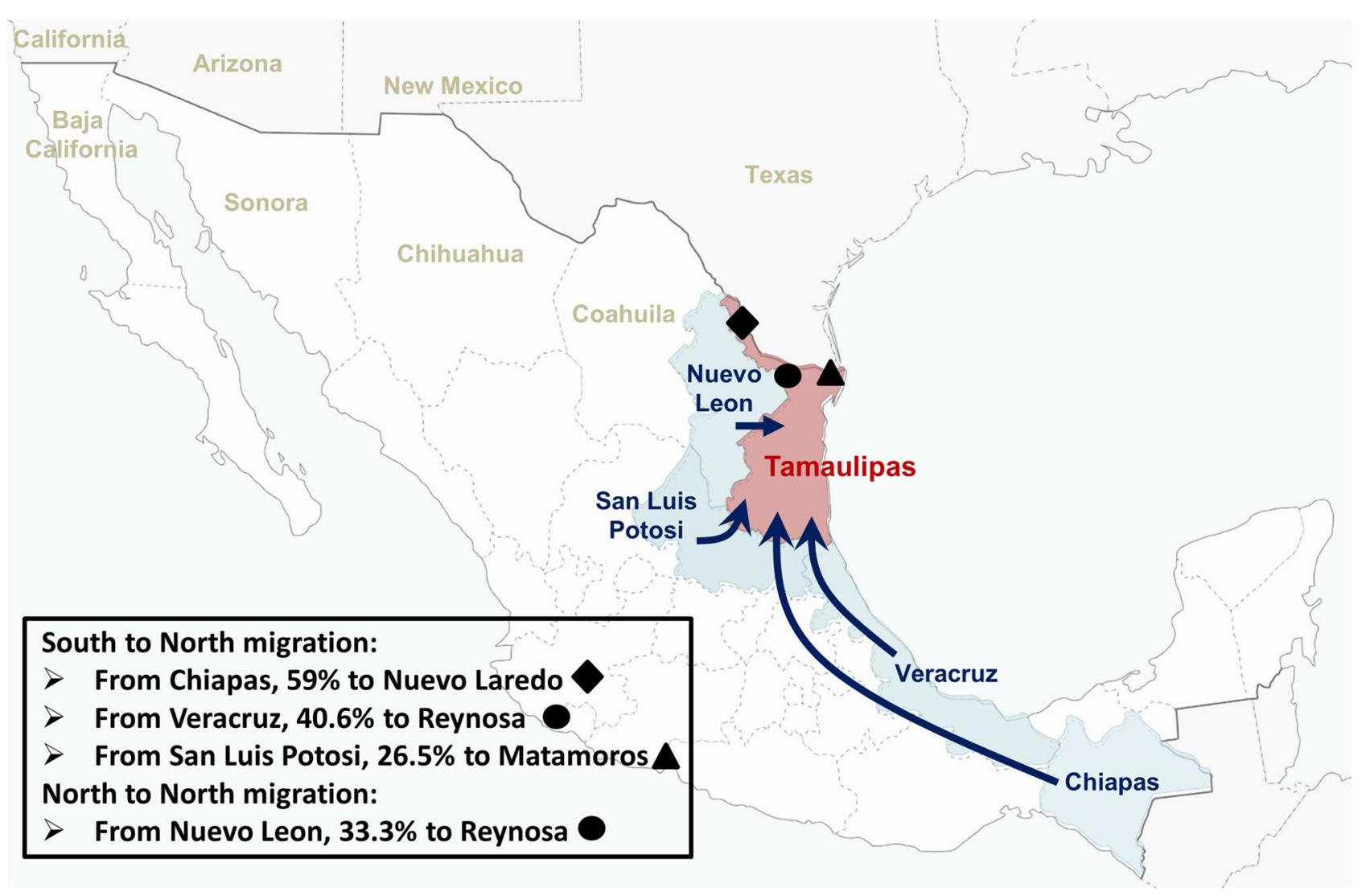

Fig. 1 Predominant south to north migration patterns of TB patients from Tamaulipas. The predominant migration patterns of TB patients diagnosed in Tamaulipas is from South and North, and to a lesser extent, from North to North. The south to north routes were from Chiapas (in the Southern border with Guatemala) to Nuevo Laredo, or Veracruz to Reynosa or San Luis Potosi to Matamoros. The north to north pattern was from Nuevo Leon to Reynosa. In all cases, the

represented one-third of the TB patients, with $>99 \%$ originating from other Mexican states. Among TB patients, immigrants were older than local-born residents. This was unexpected given that immigrants are usually young and able to travel [1]. In our study, it is possible that immigrants arrived to Tamaulipas when they were younger. They may have brought with them a latent TB infection that progressed to reactivation to active TB years later- at the time of this study. Alternatively, they may have had a recent exposure to a TB case with primary progressive TB - we cannot distinguish both possibilities given our cross-sectional study design. Consistent with their older age, immigrants with TB had lower levels of education, higher prevalence of diabetes and lower BCG vaccination as we have described recently [25]. Given our recent finding that lack of BCG vaccination at birth is independently associated with higher odds of TB in the elderly, it is possible that convergence of these two host factors in immigrants contribute to their development of TB [25] (Table 3). final destination cities, namely Matamoros, Reynosa and Nuevo Laredo, were in northern Tamaulipas and adjacent to the US border. The proportion of immigrants from each place of origin, towards the indicated destination, is shown in the legend for each pathway. The names of the other states along the US-Mexico border as shown as a reference in lighter font

TB immigrants worldwide may be less likely to have treatment success due to various reasons: (i) treatment interruption due to their mobile living conditions, (ii) barriers to access treatment (e.g., economic constraints, fear of deportation), and (iii) policy of the host country to provide free TB treatment [26, 27]. In our study, abandoning of treatment was not a signature of immigrants as a whole, nor among those arriving from San Luis Potosi or Chiapas in particular, which are ranked 22nd and 32nd for Human Development Index, respectively, among the 32 Mexican states [28, 29]. In contrast, abandonment of treatment was only significant for immigrants born in Nuevo Leon, which has a very high human development index (ranked 3rd) [29]. The fact that loss to follow-up during treatment was not as prevalent in our immigrant population may be supported by: (i) the older profile of immigrants who may be already settled in Tamaulipas; (ii) Most immigrant TB patients were from out of state, and not illegal aliens from another country that could increase their fear of reporting to health authorities 
Table 1 Demographic and clinical characteristics of TB patients by place of birth in Tamaulipas, 2006-2013

\begin{tabular}{|c|c|c|c|c|}
\hline Characteristics & $\begin{array}{l}\text { Born in Tamaulipas } \\
(\mathrm{n}=5835)\end{array}$ & $\begin{array}{l}\text { Not born in Tamaulipas } \\
(\mathrm{n}=2596)\end{array}$ & OR $(95 \% \mathrm{CI})^{\mathrm{a}}$ & $\begin{array}{l}\text { Adj-OR } \\
(95 \% \mathrm{CI})^{\mathrm{b}}\end{array}$ \\
\hline \multicolumn{5}{|c|}{ Sociodemographics and comorbidities } \\
\hline \multicolumn{5}{|l|}{ Age } \\
\hline $18-40$ years old & $3038(52.1 \%)$ & $1023(39.4 \%)$ & 1.0 & \\
\hline 41-64 years old & $2219(38 \%)$ & $1108(42.7 \%)$ & $1.5(1.3,1.6)$ & \\
\hline$\geq 65$ years old & $578(9.9 \%)$ & $465(17.9 \%)$ & $2.4(2.1,2.8)$ & \\
\hline Male sex & $3849(66 \%)$ & $1674(64.5 \%)$ & $0.9(0.8,1.03)$ & \\
\hline \multicolumn{5}{|l|}{ Education } \\
\hline $\begin{array}{l}\text { No or primary educa- } \\
\text { tion }\end{array}$ & $3103(55.9 \%)$ & $1574(62.1 \%)$ & $1.3(1.2,1.4)$ & \\
\hline Higher education & 2447 (44.1\%) & $960(37.9 \%)$ & 1.0 & \\
\hline \multicolumn{5}{|l|}{ Occupation } \\
\hline Employed & $1848(42.9 \%)$ & $781(41.2 \%)$ & 1.0 & 1.0 \\
\hline Not employed & $1788(41.5 \%)$ & $843(44.5 \%)$ & $1.1(0.9,1.3)$ & $0.9(0.8,1.0)$ \\
\hline Unemployed & $669(15.5 \%)$ & $271(14.3 \%)$ & $0.9(0.8,1.1)$ & $0.9(0.7,1.0)$ \\
\hline BCG (Yes) & $4211(77 \%)$ & $1783(74.6 \%)$ & $0.9(0.8,0.98)$ & $1.1(0.9,1.2)$ \\
\hline \multicolumn{5}{|l|}{ Comorbidities } \\
\hline Diabetes & $1397(23.9 \%)$ & $724(27.9 \%)$ & $1.2(1.1,1.4)$ & $01.0(0.9,1.1)$ \\
\hline HIV/AIDS & $332(5.7 \%)$ & $113(4.3 \%)$ & $0.7(0.6,0.9)$ & $0.9(0.7,1.1)$ \\
\hline Excess alcohol use & $344(5.9 \%)$ & $130(5 \%)$ & $0.8(0.7,1.1)$ & $0.8(0.7,1.0)$ \\
\hline Undernutrition & $474(8.1 \%)$ & $226(8.7 \%)$ & $1.1(0.9,1.3)$ & $1.1(0.9,1.3)$ \\
\hline \multicolumn{5}{|l|}{ Clinical presentation of $\mathrm{TB}$} \\
\hline \multicolumn{5}{|l|}{ Location of disease } \\
\hline Extra-pulmonary & $470(8.1 \%)$ & $206(7.9 \%)$ & 1.0 & 1.0 \\
\hline Pulmonary & $5364(91.9 \%)$ & $2390(92.1 \%)$ & $1.0(0.8,1.2)$ & $0.9(0.8,1.2)$ \\
\hline AFB smear & $4629(85.8 \%)$ & $1982(83.5 \%)$ & $0.8(0.7,0.9)$ & $0.8(0.7,0.9)$ \\
\hline Any drug resistance & $179(3.1 \%)$ & $80(3.1 \%)$ & $1.0(0.8,1.3)$ & $1.0(0.8,1.4)$ \\
\hline Multi-drug resistance & $40(0.7 \%)$ & $15(0.6 \%)$ & $0.8(0.5,1.5)$ & $0.9(0.5,1.7)$ \\
\hline \multicolumn{5}{|l|}{ Treatment outcomes } \\
\hline Cured & $4874(85.1 \%)$ & $2135(83.9 \%)$ & 1.0 & 1.0 \\
\hline Treatment failure & $107(1.9 \%)$ & $51(2 \%)$ & $1.1(0.8,1.5)$ & $1.1(0.7,1.5)$ \\
\hline Death & $354(6.2 \%)$ & $167(6.6 \%)$ & $1.1(0.9,1.3)$ & $0.9(0.7,1.1)$ \\
\hline Abandon treatment & $390(6.8 \%)$ & $191(7.5 \%)$ & $1.1(0.9,1.3)$ & $1.2(1.0,1.5)$ \\
\hline TB relapse & $126(2.2 \%)$ & $48(1.9 \%)$ & $0.8(0.6,1.2)$ & $0.8(0.6,1.2)$ \\
\hline
\end{tabular}

Data expressed as n (column \%), with \% based on the total number of cases with available information

${ }^{\text {a }}$ Tamaulipas is the reference category

${ }^{\mathrm{b}}$ Adjusted for age, sex, and education level; Bold p-values are significant when seeking treatment; (iii) The Mexican National Tuberculosis Program provides free treatment to all TB patients [30]. Thus, our findings are in contrast to the profile of some immigrants who are young refugees, asylum seekers or illegal aliens, who are under significant stress and develop TB while moving to other countries.

Mexico has a total population of approximately 126 million, with close to $50 \%$ living in poverty [31, 32]. Economic insecurity and drug and human trafficking cartels are main propagators of Mexican internal migration movements, with about $20 \%$ of the population living in states in which they were not born [32-35]. It is locally believed that migration from the poorest regions in Mexico may be responsible for a significant proportion of TB cases in the Mexican states located across the US border, but this has never been systemically evaluated. A study conducted 25 years ago among immigrant TB patients identified at local health departments at the four US border states, provides some insights [36]. Of the 164 Hispanic immigrant TB patients, 154 were born in Mexico and ten in Central America. Among the 154 born in Mexico, 93 (60\%) had been living in a border Mexican town before emigrating to the US, and of these 93, 51 (55\%) had first moved to a Mexican border town for at least 2 years before emigrating to the US. The findings from this study 
Table 2 Association between the most common places of birth of migrants, and sociodemographics, comorbidities, TB presentation and treatment outcomes

\begin{tabular}{|c|c|c|c|c|}
\hline Place of birth & $\begin{array}{l}\text { Chiapas } \\
(n=181)\end{array}$ & $\begin{array}{l}\text { Nuevo Leon } \\
(\mathrm{n}=255)\end{array}$ & $\begin{array}{l}\text { San Luis Potosi } \\
(\mathrm{n}=476)\end{array}$ & $\begin{array}{l}\text { Veracruz } \\
(\mathrm{n}=903)\end{array}$ \\
\hline \multicolumn{5}{|c|}{ Sociodemographics and comorbidities } \\
\hline \multicolumn{5}{|l|}{ Age } \\
\hline $18-40$ years old & 1.0 & 1.0 & 1.0 & 1.0 \\
\hline 41-64 years old & $1.5(1.1,2.2)$ & $2.1(1.6,2.8)$ & $2.3(1.8,2.8)$ & $1(0.9,1.2)$ \\
\hline$\geq 65$ years old & $3.5(2.3,5.2)$ & $3.6(2.5,5.1)$ & $4.4(3.4,5.7)$ & $0.9(0.8,1.3)$ \\
\hline Male sex & $1.2(0.9,1.6)$ & $0.9(0.7,1.1)$ & $0.9(0.7,1.1)$ & $0.9(0.8,1.0)$ \\
\hline \multicolumn{5}{|l|}{ Education } \\
\hline Higher education & 1.0 & 1.0 & 1.0 & 1.0 \\
\hline Up to 1 o education & $1.8(1.3,2.5)$ & $1.6(1.2,2.0)$ & $1.9(1.5,2.3)$ & $0.9(0.8,1.1)$ \\
\hline \multicolumn{5}{|l|}{ Occupation } \\
\hline Employed & 1.0 & 1.0 & 1.0 & 1.0 \\
\hline Not employed & $1.4(0.9,2.0)$ & $1.3(0.9,1.8)$ & $1.2(0.9,1.6)$ & $0.9(0.8,1.1)$ \\
\hline Unemployed & $1.2(0.7,2.0)$ & $1.2(0.7,1.8)$ & $1.2(0.8,1.6)$ & $0.9(0.7,1.1)$ \\
\hline BCG (Yes) & $0.8(0.6,1.2)$ & $1(0.8,1.4)$ & $1.1(0.8,1.3)$ & $0.9(0.8,1.1)$ \\
\hline \multicolumn{5}{|l|}{ Comorbidities } \\
\hline Diabetes & $0.9(0.6,1.3)$ & $1.2(0.9,1.6)$ & $1.6(1.3,1.9)$ & $1.2(1.1,1.4)$ \\
\hline HIV & $0.2(0.04,0.7)$ & $0.5(0.3,1.1)$ & $0.5(0.3,0.9)$ & $1.3(0.9,1.7)$ \\
\hline Excess alcohol use & $0.7(0.4,1.5)$ & $0.8(0.5,1.5)$ & $0.9(0.6,1.4)$ & $0.8(0.6,1.1)$ \\
\hline Malnutrition & $1.3(0.8,2.1)$ & $0.8(0.5,1.3)$ & $1(0.7,1.4)$ & $1.1(0.9,1.4)$ \\
\hline \multicolumn{5}{|l|}{ Clinical presentation of TB } \\
\hline \multicolumn{5}{|l|}{ Location of disease } \\
\hline Extra-pulmonary & 1.0 & 1.0 & 1.0 & 1.0 \\
\hline Pulmonary & $1.5(0.8,2.9)$ & $1.2(0.7,1.9)$ & $1.1(0.8,1.6)$ & $0.9(0.7,1.2)$ \\
\hline Diagnostic AFB smear & $1.2(0.7,1.9)$ & $0.9,(0.6,1.3)$ & $0.8(0.6,1.1)$ & $0.7(0.6,0.8)$ \\
\hline Any drug resistance & $0.7(0.3,1.9)$ & $1.2(0.6,2.3)$ & $0.6(0.3,1.2)$ & $0.8(0.5,1.2)$ \\
\hline Multi-drug resistance & $1.6(0.4,6.7)$ & $1.1(0.3,4.8)$ & $0.9(0.3,2.9)$ & $0.3(0.1,1.3)$ \\
\hline \multicolumn{5}{|l|}{ Treatment outcomes } \\
\hline Cured & 1.0 & 1.0 & 1.0 & 1.0 \\
\hline Treatment failure & $0.9(0.3,2.9)$ & $2.0(1.1,4.1)$ & $1.3(0.7,2.5)$ & $0.8(0.4,1.4)$ \\
\hline Death & $1.2(0.7,2.1)$ & $1.0(0.6,1.8)$ & $1.1(0.8,1.6)$ & $0.9(0.7,1.3)$ \\
\hline Abandon treatment & $1.1(0.6,1.9)$ & $1.5(0.9,2.3)$ & $0.6(0.4,1.0)$ & $1.2(0.9,1.6)$ \\
\hline TB relapse & $2.1(1.1,4.3)$ & $1.3(0.6,2.8)$ & $0.7(0.3,1.5)$ & $0.5(0.3,0.9)$ \\
\hline
\end{tabular}

Tamaulipas is the reference category. Data expressed as crude odds ratio $(95 \% \mathrm{CI})$

Bold values indicate significant differences $(p<0.05)$ illustrates the influx of immigrants from non-border Mexican regions, into the border, and then into the USA, suggesting the importance of TB control in border and non-border regions of Mexico for control of TB in communities along the Texas-Mexico border [36]. Our findings provide support for the importance of inquiring on the place of birth as an additional epidemiological risk for TB in these border communities.

A limitation of our study is that the analysis covered a period dating seven to fourteen years back. We do not have data on the proportion of immigrant TB patients in more recent years, but we would anticipate an increase. This is based on the regional trend for the increase in caravans of immigrants departing from South and Central American and
Caribbean countries where TB is also endemic, with hopes of reaching the US, but with many remaining stuck in northern Mexico [37, 38]. Tamaulipas is a "Remain in Mexico" (RIM) state under the Immigrant Protection Protocols (MPP) implemented in 2019 with top immigrant nationalities from Honduras, Guatemala, Cuba, El Salvador, Haiti and Ecuador. These policies highlight the epidemiological landscape of the Mexican border communities. Thus, we expect that in current times the proportion of immigrants with TB is more than our observed $30 \%$ - which is already very high. We further anticipate there may be a shift in epidemiology from older out of state Mexican individuals with diabetes, to international and younger immigrants, including children, living under crowded makeshift conditions at the border, and 
Table 3 Association between the place of birth of migrants and the clinical presentation and outcomes of TB

\begin{tabular}{lllll}
\hline Place of birth & $\begin{array}{l}\text { Chiapas } \\
(\mathrm{n}=181)\end{array}$ & $\begin{array}{l}\text { Nuevo Leon } \\
(\mathrm{n}=255)\end{array}$ & $\begin{array}{l}\text { San Luis Potosi } \\
(\mathrm{n}=476)\end{array}$ & $\begin{array}{l}\text { Veracruz } \\
(\mathrm{n}=903)\end{array}$ \\
\hline $\begin{array}{l}\text { Location of disease } \\
\text { Extra-pulmonary }\end{array}$ & 1.0 & & & \\
$\quad$ Pulmonary & $1.3(0.7,2.7)$ & $1.1(0.6,1.8)$ & $0.9(0.7,1.4)$ & $0.9(0.7,1.3)$ \\
Diagnostic AFB smear & $1.1(0.7,1.8)$ & $0.8,(0.6,1.2)$ & $0.7(0.5,0.9)$ & $0.7(0.6,0.9)$ \\
Any drug resistance & $0.6(0.2,2.0)$ & $1.1(0.6,2.3)$ & $0.7(0.3,1.4)$ & $0.8(0.5,1.2)$ \\
Multi-drug resistance & $1.2(0.2,8.8)$ & $0.93(0.1,5.1)$ & $1.0(0.3,3.5)$ & $0.3(0.1,1.6)$ \\
Treatment outcomes & & & & \\
$\quad$ Cured & 1.0 & 1.0 & 1.0 & 1.0 \\
Treatment failure & $1.1(0.3,3.4)$ & $2.0(0.9,4.1)$ & $1.2(0.6,2.4)$ & $0.9(0.5,1.7)$ \\
$\quad \begin{array}{l}\text { Death } \\
\text { Abandon treatment }\end{array}$ & $1.2(0.6,2.2)$ & $0.8(0.4,1.5)$ & $0.9(0.6,1.3)$ & $0.9(0.7,1.3)$ \\
TB relapse & $1.3(0.7,2.4)$ & $\mathbf{1 . 9}(\mathbf{1 . 2}, \mathbf{2 . 9})$ & $0.7(0.4,1.2)$ & $1.2(0.9,1.6)$ \\
\hline
\end{tabular}

Tamaulipas is the reference category. Data expressed as odds ratio (95\% CI), adjusted for for age, sex, education, BCG vaccination, diabetes and HIV/AIDS; $A F B$ Acid-fast bacilli

Bold values indicate significant differences $(p<0.05)$ with low body-mass index and stress of migration as risk factors for progression to TB.

Another novel aspect of immigration in contemporary times is the additional challenge to TB control during the coronavirus disease 2019 (COVID-19) pandemic. In Mexican border states, poverty, overcrowding, stress from immigration and lack of access to healthcare have contributed to high COVID-19 case-fatality rates in border Mexican states (16\% compared to $8.5 \%$ nationally in 2020) [39]. Not surprisingly, COVID-19 has had a notable impact on TB services in the US-Mexico border. This, together with immigration patterns from South to North, is likely to result in higher drug susceptible and drug resistant TB cases in the upcoming years, with potential spill over to US Border States.

Another study limitation is that we conducted a secondary analysis of data collected for TB surveillance. Therefore, we were not able to calculate the TB incidence among those born in Tamaulipas versus immigrants born elsewhere. Year of immigration was not available either, so we could distinguish between migrants who were temporarily located in Tamaulipas vs immigrants who had permanently settled in this state. Furthermore, in our analysis we could not adjust for the years of residence prior to TB diagnosis. We did not have information on the reasons motivating migration, predeparture health status, or travel conditions that can increase TB risk [40]. We cannot rule out reporting bias due to the stigma associated with migration. An association between immigrant status and drug-resistant TB was not measured. Another limitation was lack of access to the identification and treatment of latent TB infection, a key action in the pillar 1 of the current WHO End TB Strategy [41, 42].
In summary, we find that approximately one-third of the TB patients in Tamaulipas are immigrants from within Mexico, mostly originating from southern states and moving to communities along the US border. Given the recent increase in migration within Mexico due to drug-related cartels, or from Latin American countries [43], further studies are necessary to understand in more depth the underlying reasons, the detailed migration pathways, the prevalence of drugresistance and the TB treatment outcomes in this mobile population. Understanding these issues will be essential to design strategies for improved TB control in gateway states like Tamaulipas. Such studies will also serve as a model to address the challenge of migration on TB control in other regions of the US-Mexico border, in the adjacent US where immigrants comprise a significant proportion of the TB patients, or in other countries worldwide where millions migrate each year from TB-endemic regions [44].

\section{New Contributions to the Literature}

Mexico is one of the most important migration corridors worldwide, and yet, there are few studies addressing the contribution of migrants to TB. Tamaulipas is a highly dynamic state on the US-Mexico border. Here, we find that one-third of the TB patients in Tamaulipas are migrants, with a predominant south to north migration pattern, and with endpoint in cities adjacent to the US border. There is a need for prospective studies designed to elucidate further details on the motives and timing for migration, and the association between migrant status and unfavorable TB outcomes, including abandoning treatment as observed in this study. 
Supplementary Information The online version contains supplementary material available at https://doi.org/10.1007/s10903-021-01294-5.

Acknowledgements We thank all the Tamaulipas state health jurisdictions who contributed to the collection and recording of TB data, Dr. Santa Elizabeth Ceballos Liceaga from the Sistema de Vigilancia Epidemiológica de Tuberculosis y Lepra, Dirección General de Epidemiología, Secretaría de Salud de México, for providing the surveillance datasets for our analysis.

Author Contributions JSC: Conceptualization, Data analysis, interpretation, original draft of manuscript; BA: Data analysis, interpretation, edition of manuscript; MG: Conceptualization and coordination of data collection; JIG: Data analysis interpretation and edition of manuscript; MY: Data analysis interpretation and edition of manuscript; AR: Data analysis interpretation and edition of manuscript; JBT: Data analysis interpretation and edition of manuscript; BIR: Conceptualization, Project administration, Resources, data interpretation, edition of manuscript. All authors: Reviewed and approved the final version of this manuscript.

Funding Funding support was not received for conducting this study. BIR has current funding support from NIH, NIA P01-AG051428 (PI Dr. Joanne Turner) and NIAID 1R21AI144541.

Data Availability The datasets generated during and/or analyzed during the current study are available from the corresponding author on reasonable request.

\section{Declarations}

Conflict of interest All authors declare that they have no conflict of interest.

Ethical Approval This study was approved by the institutional review board of the University of Texas Health Science Center at Houston (Human Subject IRB \# HSC-SPH-15-0489) and the Research Committee for the Secretaría de Salud de Tamaulipas (Human Subjects IRB\# 076/2015/CEI). This study was performed in accordance with the ethical standards as laid down in the 1964 Declaration of Helsinki and its later amendments or comparable ethical standards.

Standards of Reporting This study followed the Strengthening the Reporting of Observational Studies in Epidemiology (STROBE) reporting guidelines.

\section{References}

1. Pareek M, et al. The impact of migration on tuberculosis epidemiology and control in high-income countries: a review. BMC Med. 2016;14:48.

2. Centers for Disease Control and Prevention (CDC). Table 9. Tuberculosis cases and percentages, by multidrug resistance (MDR), Origin of birth, and previous history of TB: United States, 1993-2019 Atlanta, GA: US: Department of Health and Human Services, Centers for Disease Control and Prevention; 2020 [updated 10-2020]. Available from https://www.cdc.gov/ tb/statistics/reports/2019/table9.htm.
3. Tsang CA, et al. Tuberculosis among foreign-born persons diagnosed $\geq 10$ years after arrival in the United States, 2010-2015. MMWR Morb Mortal Wkly Rep. 2017;66(11):295-8.

4. Bojorquez-Chapela I, et al. Multidrug-resistant tuberculosis among patients in Baja California, Mexico, and Hispanic patients in California. Am J Public Health. 2013;103(7):1301-5.

5. Centers for Disease Control and Prevention (CDC). Table 28. Tuberculosis cases and case rates per 100,000 population: reporting areas, 2019 and 2018 Atlanta, GA: US: Department of Health and Human Services, Centers for Disease Control and Prevention; 2020 [updated 10-2020]. Available from https://www.cdc.gov/tb/ statistics/reports/2019/table28.htm. Accessed 13 Oct 2021.

6. Fitchett JRA. Tuberculosis transmission across the United StatesMexico border. Revista Panamericana de Salud Publica/Pan Am J Public Health. 2011;29(1):57-60.

7. CDC's Atlas Plus [Internet]. Centers for Disease Control and Prevention. 2020. Available from https://www.cdc.gov/nchhstp/atlas/ index.htm. Accessed 23 Sep 2021

8. Restrepo BI, et al. Cross-sectional assessment reveals high diabetes prevalence among newly-diagnosed tuberculosis cases. Bull WHO. 2011;89(5):352-9.

9. Consejo Nacional de Ciencia y Tecnologia (CONACYT). COVID19 México [web]. Gobierno de México, CONACYT; 2021 [updated 2021-01-31. Official COVID-19 statistics for Mexico in real time]. Available from https://datos.covid-19.conacyt.mx/. Accessed 13 Jun 2021

10. Deiss R, et al. Influences of cross-border mobility on tuberculosis diagnoses and treatment interruption among injection drug users in Tijuana, Mexico. Am J Public Health. 2009;99(8):1491-5.

11. Kenyon TA, et al. Immigration and tuberculosis among children on the United States-Mexico border County of San Diego California. Pediatrics. 1999;104(1):e8.

12. Moya EM, et al. Nuestra Casa: an advocacy initiative to reduce inequalities and tuberculosis along the US-Mexico border. Int Public Health J. 2016;8(2):107-19.

13. CONACYT. COVID-19 México [web]. https://datos.covid-19. conacyt.mx/: Gobierno de México, CONACYT; 2021 [updated 2021-01-31. Official COVID-19 statistics for Mexico in real time]. Available from https://datos.covid-19.conacyt.mx/. Accessed 12 Jun 2021.

14. Oren E, et al. Detection of latent tuberculosis infection among migrant farmworkers along the US-Mexico border. BMC Infect Dis. 2016;16(1):630.

15. Bojorquez-Chapela I, et al. Drug resistance in Mexico: results from the national survey on drug-resistant tuberculosis. Int $\mathrm{J}$ Tuberc Lung Dis. 2013;17(4):514-9.

16. Centro Nacional de Programas Preventivos y Control de Enfermedades (CENAPRECE). Cifras oficiales tuberculosis Mexico: CENAPRECE, Centro Nacional de Programas Preventivos y Control de Enfermedades de Mexico; 2016 Available from http:// www.cenaprece.salud.gob.mx/programas/interior/micobacter iosis/tuberculosis/cifras_oficiales.html\#. Accessed 12 Jun 2021.

17. Hernández-Garduño $\mathrm{E}$, et al. Tuberculosis in Mexico and the USA, comparison of trends over time 1990-2010. Tuberc Respir Dis. 2015;78(3):246-52.

18. Valencia CI, et al. Tuberculosis treatment completion in a United States/Mexico binational context. Front Public Health. 2017. https://doi.org/10.3389/fpubh.2017.00118.

19. International Organization for Migration, and United Nations. World Migration Report 2013. Geneva: International Organization for Migration, 2013. Available from https://www.iom.int/wmr/ interactive/; https://www.youtube.com/watch?v=2xcJ8zonWGg.

20. Integration and Building Inclusive Societies. United Nations Alliance of Civilizations 2010. Available from http://www.unaoc.org/ ibis/2010/09/09/background-research-on-mexico-city/. 
21. Secretaría de Salud, Gobierno del Estado de Tamaulipas. Unidades y Jurisdicciones en el Estado de Tamaulipas: Gobierno del Estado de Tamaulipas; 2015 Available from: http://salud.tamau lipas.gob.mx/infraestructura/jurisdicciones-sanitarias/.

22. Jurisdicciones Sanitarias. Tamaulipas Secretaría de Salud 2015. Available from: http://salud.tamaulipas.gob.mx/infraestructura/ jurisdicciones-sanitarias/.

23. Abdelbary BE, et al. Tuberculosis-diabetes epidemiology in the border and non-border regions of Tamaulipas, Mexico. Tuberculosis (Edinb). 2016;101S:S124-34.

24. World-Health-Organization. Definitions and reporting framework for tuberculosis- 2013 revision (updated Dec 2014 and Jan 2020). 2021. Available from: https://apps.who.int/iris/handle/10665/ 79199.

25. Scordo JM, et al. A prospective cross-sectional study of tuberculosis in elderly Hispanics reveals that BCG vaccination at birth is protective whereas diabetes is not a risk factor. PLoS ONE. 2021;16(7):e0255194.

26. Vo LNQ, et al. Tuberculosis among economic migrants: a crosssectional study of the risk of poor treatment outcomes and impact of a treatment adherence intervention among temporary residents in an urban district in Ho Chi Minh City, Viet Nam. BMC Infect Dis. 2020;20(1):134.

27. Chemtob D, Ogum E. Tuberculosis treatment outcomes of noncitizen migrants: Israel compared to other high-income countries. Isr J Health Policy Res. 2020;9(1):29.

28. Villafuerte-Solis D. Crisis rural, pobreza y hambre en Chiapas. LiminaR. 2015;13(1):13.

29. Permanyer I, Smits J. The subnational human development index: moving beyond country-level averages. 2018. http://hdr.undp. org/en/content/subnational-human-development-index-movingbeyond-country-level-averages. Accessed 31 May 2018.

30. Programa de Acción Específico: Prevención y Control de la Tuberculosis 2013-2018. Secretaria de Salud de México y CENAPRECE, 2018 2018. https://www.gob.mx/salud/documentos/progr ama-de-accion-especifico-prevencion-y-control-de-la-tuberculos is-2013-2018. Accessed 12 Jun 2021.

31. Consejo Nacional de Evaluacin de la Politica de Desarrollo Social (CONEVAL). Medición de la Pobreza 2008-2018 2014. Available from http://www.coneval.gob.mx/Medicion/MP/Paginas/Pobreza2014-en.aspx.

32. Instituto Nacional de Estadística y Geografía (INEGI). Censo de Poblacion y Vivienda 2020. Instituto Nacional de Estadística y
Geografía 2020. 2020. Available from: https://www.inegi.org.mx/ temas/estructura/.

33. Martinez JN. Beyond networks: health, crime, and migration in Mexico. Int J Popul Res. 2014;2014:971739.

34. Hernandez D. Internal migration flows below the radar in Mexico. Los Angeles Times 2011. Available from: http://latimesblogs. latimes.com/laplaza/2011/08/drug-war-refugees-violence-asylum-mexico.html.

35. Mexican Migration Patterns Signal a New Immigration Reality. Americam Immigration Council 2011. Available from: http:// immigrationpolicy.org/just-facts/mexican-migration-patternssignal-new-immigration-reality.

36. Moser K, et al. Characteristics of foreign-born Hispanic patients with tuberculosis - eight U.S. counties bordering Mexico, 1995. Morb Mortal Wkly Rep. 1996;45(47):1032-6.

37. Latin America Working Group (LAGW). All about the "Remain in Mexico" policy 2021. Available from https://www.lawg.org/ all-about-the-remain-in-mexico-policy/. Accessed 12 Jun 2021.

38. Medecins Sans Frontiers (MSF). US migration policy endangers lives of asylum seekers in Tamaulipas state 2020. Available from https://www.msf.org/us-migration-policy-endangers-lives-asylum-seekers-tamaulipas-state-mexico. Accessed 12 Jun 2021.

39. Google. Google News: COVID-2019: Google; 2021 [updated 2021-02. Worldwide statistics for COVID-19 cases and deaths in real time]. Available from https://news.google.com/covid19/map? $\mathrm{hl}=\mathrm{en}-\mathrm{US} \& \mathrm{gl}=\mathrm{US} \& \mathrm{ceid}=\mathrm{US} \% 3 \mathrm{Aen} \& \mathrm{mid}=\% 2 \mathrm{Fm} \% 2 \mathrm{~F} 0 \mathrm{~b} 90 \_\mathrm{r}$. Accessed 12 Jun 2021.

40. Dhavan P, et al. An overview of tuberculosis and migration. Int J Tuberc Lung Dis. 2017;21(6):610-23.

41. World Health Organization (WHO). The End TB Strategy. Geneva: World Health Organization, 2015 Contract No.: WHO/ HTM/TB/2015.19.

42. Uplekar M, Raviglione M. WHO's end TB strategy: from stopping to ending the global TB epidemic. Indian J Tuberc. 2015;62(4):196-9.

43. Basu S, Pearlman S. Violence and migration: evidence from Mexico's drug war. IZA J Develop Migration. 2017;7(1):18.

44. Rendon A, et al. Migration, TB control and elimination: whom to screen and treat. Pulmonology. 2018;24(2):99-105.

Publisher's Note Springer Nature remains neutral with regard to jurisdictional claims in published maps and institutional affiliations. 